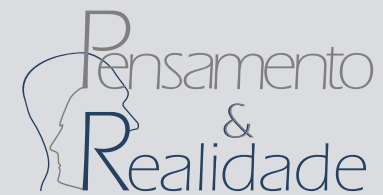

\title{
PLANEJAMENTO E EXECUÇÃO ESTRATÉGICA: AS DIVERGÊNCIAS NO PROCESSO.
}

Ana Valéria Barbosa da Silva

Francisco Antonio Serralvo ${ }^{2}$

Paulo Romaro ${ }^{3}$

\section{Resumo}

O tema estratégia remete a refletir inicialmente sobre planejar e pode induzir o gestor a se preocupar com diagnósticos, análises, identificação de posicionamentos e a busca pela tão almejada vantagem competitiva sustentável. Essa reflexão necessita também que se designe atenção de maneira simultânea à sua execução com seus desdobramentos e obstáculos. Neste estudo o objetivo foi identificar os obstáculos que levam estratégias com potencial de sucesso a não atingirem os resultados esperados. Soma-se assuntos correlatos que merecem atenção para que essa formulação e execução aconteçam de modo eficaz destacando temas como complexidade, modos diversos de se pensar estratégia e papel dos gestores. A pesquisa de campo, por meio de um estudo de caso, ocorreu em uma representativa Instituição Financeira Brasileira Governamental onde aplicou-se 1020 questionários com um retorno de 380 respondentes cujos dados foram tratados por meio de análise fatorial exploratória utilizando o programa SPSS. O resultado obtido reforça as conclusões de autores referenciados neste estudo como Heide, Gronhaug e Johannessen (2002), Ritson, Johansen e Osborne (2012) e Hrebiniak (2013), mas também demonstra que a relevância dos fatores encontrados pode ser diferente. O obstáculo referente à comunicação apresentou grande destaque.

Palavras-Chave:Estratégia;Planejamento;Execução;VantagemCompetitiva;Resultados.

\section{STRATEGIC PLANNING AND EXECUTION: PROCESS DIVERGENCES.}

\section{Abstract}

The strategy theme leads initially to reflect on planning and can induce the manager to worry about diagnoses, analysis, identification of positions and the search for the long-sought sustainable competitive advantage. This reflection also needs attention to be given simultaneously to its execution with its unfolding and obstacles. In this study the objective was to identify the obstacles that lead strategies with potential for success not to achieve the expected results. Related subjects are added that deserve attention so that this formulation and execution happen effectively highlighting topics such as complexity, different ways of thinking strategy and role of managers. The field research, through a case study, took place in a representative Brazilian Governmental Financial Institution where it was applied 1020 questionnaires with a return of 380 respondents whose data were processed through exploratory factor analysis using the SPSS program. The result obtained reinforces the conclusions of authors referenced in this study such as Heide, Gronhaug and Johannessen (2002), Ritson, Johansen and Osborne (2012) and Hrebiniak (2013), but also demonstrates that the relevance of the factors found may be different. The communication obstacle was highlighted.

Keywords: Strategy; Planning; Execution; Competitive advantage; Results.

1 - Pontifícia Universidade Católica de São Paulo

2 - Pontifícia Universidade Católica de São Paulo

3 - Pontifícia Universidade Católica de São Paulo 


\section{Introdução}

O contexto do planejamento estratégico das organizações enfrenta desafios no que se refere ao momento da sua execução resultando, quase sempre, em divergências entre ações projetadas e realizadas, refletindo em divergências entre resultados projetados e alcançados.

As organizações são orientadas por suas estratégias, o que significa ter feito escolhas racionais, com definições de objetivos, por um projeto ou um plano para atingir esses propósitos, que é diferente de apenas definir metas de crescimento e/ou financeiras. Tais organizações esforçam-se para traduzir as orientações estratégicas na prática durante a execução de seus planejamentos, utilizando ferramentas de comunicação entre o topo e a base, pois a execução da estratégia é tão importante quanto desenvolver uma estratégia de qualidade. Porém, verifica-se divergência entre as estratégias formalmente deliberadas e as executadas efetivamente (Mintzberg, 2004). No contexto global e tecnológico atual as tomadas de decisões estratégicas imprescindem de planejamento, velocidade, efetividade e inovação. A sobrevivência em ambientes turbulentos e desafiadores, obriga as organizações a escolher direções estratégicas que sejam convertidas em realização dos objetivos propostos, já que pensar estrategicamente é diferente de planejar estrategicamente (Mintzberg, 2004).

Conforme Besanko, Dranove, Shanley e Schaefer (2018) as organizações devem considerar quatro fatores no processo de formulação estratégica: 1) fronteiras da empresa que é a definição do que será feito/produzido, em quais negócios a empresa irá se envolver e qual tamanho; 2) análise de mercado e concorrência que esclarecerá sobre o ambiente em que se está inserido e as relações dos stakeholders; 3) posicionamento e dinâmica que definem o como competir e qual será a vantagem competitiva; e 4) a organização interna que delimita a estrutura necessária para alcance dos objetivos.
A elaboração estratégica nasce de ações explícitas, proativas e racionais dentro de um processo coordenado e dirigido para o atingimento dos objetivos organizacionais, conforme Ansoff e McDonnell (1988), e que as mesmas, a despeito de sua clareza e qualidade estruturais, podem não trazer os resultados esperados. Identificar por que estratégias que levam em consideração as questões relevantes, como as identificadas por Besanko et. al. (2018), em sua formulação e que terão relação direta com as chances de sucesso em sua execução, nem sempre alcançam os resultados esperados é a questão aqui apresentada. Torna-se imprescindível analisar diversos aspectos dentro e fora da organização para que se possa identificar como e por que isso ocorre. Através da literatura existente e da pesquisa de campo realizada, buscou-se ressaltar os fatores chave que podem afetar os resultados estratégicos projetados pela organização.

\section{Revisão da Literatura}

\subsection{Estudos sobre o tema}

O planejamento estratégico é indispensável ao se buscar, através dele e fazendo escolhas, mitigar riscos, construir e sustentar vantagens competitivas. Porém, mesmo em organizações com planos estratégicos bem elaborados, identifica-se uma dificuldade na execução desses planos, pois nem tudo que é planejado chega a ser executado; ou ainda é executado de maneira diversa às definições iniciais. Ao estudar as realidades organizacionais é possível identificar relatos de planejamentos elaborados por longos períodos com a utilização de uma gama de recursos, ferramentas e informações; chegando a escolhas estratégicas aparentemente bem estruturadas, mas que não foram executadas como deveriam. E, aí, surge a pergunta: O que aconteceu de errado? Identifica-se que entre a formulação e a execução estratégica se faz necessária a tentativa e, mais ainda, a capacidade de identificação e correção de equívocos para o alcance final dos objetivos. Mintzberg (2006) identifica que culturas organizacionais 
que separam formulação e execução podem enveredar por caminhos incoerentes com o sucesso estratégico desejado. É improvável um sucesso empresarial sem clareza de rumo, sem estratégias bem desenhadas e sem uma consequente e alinhada execução. A habilidade para implementar escolhas estratégicas é uma competência gerencial indispensável, porém, há uma percepção ao buscar estudos sobre o assunto de que um número significativo de empresas não chega a termo com suas execuções estratégicas. As pesquisas de Beer e Eisenstat (2000), Bossidy e Charan (2005), Hrebiniak (2008), Crittenden e Crittenden (2008) e Cocks (2010) embasam a presente afirmação.

Segundo Aldemir Drummond, coordenador da Fundação Dom Cabral, todas as dificuldades encontradas pelos executivos estão relacionadas à falta de planejamento da implementação e apoiadas na crença de que a execução é apenas uma consequência de um plano bem estruturado, crença essa contestada por autores como Hrebiniak (2013).

$\mathrm{Na}$ realidade organizacional deveria-se repensar as maneiras tradicionais de executar as estratégias competitivas já que, em um mundo globalizado, questões culturais e do comportamento humano devem ser consideradas como fatores com maior relevância na formatação da execução. Deve-se também, avaliar a complexidade do mundo atual entendendo que ao aplicar estratégias que tiveram sucesso anteriormente em situações diferentes pode levar a resultados indesejados. $\mathrm{O}$ contexto tem total influência sobre os resultados organizacionais (Mitchell, Larson, Colantonio, \& Nguyen 2018).

Mesmo com a realização de escolhas com base em cenários amplos e complexos que buscam diminuir a vulnerabilidade, a incerteza é fato. Segundo Dutra e Erdmann (2007), as organizações são "sistemas complexos adaptativos" onde é inerente a capacidade de adequação reagindo às "alterações ambientais." A linearidade estável, a total ordem sem qualquer desordem, é uma utopia. Por outro lado, ser gestor somente na "ordem", limita a ação e a criatividade. E onde somente há desordem tem-se o caos (Bauer, 1999). O que torna ainda mais importante pensar no tempo da execução, entendendo que não há uma receita para a execução, mas há fatores que devem ser considerados que obstaculizam o bom desempenho. Bauer (1999) destaca que as empresas planejam e fazem escolhas, mas, não têm como controlar todos os desdobramentos, já que as relações internas e externas às empresas podem produzir uma infinita gama de imprevistos. A complexidade é fato.

A existência e a necessidade da estratégia apresentam-se desde os primórdios da humanidade, mesmo não recebendo inicialmente essa denominação (Freedman, 2015). Com o avanço da evolução humana e a consequente estruturação organizacional, mostrou-se como necessidade o gerenciamento estratégico dessas organizações. $\mathrm{O}$ aumento da complexidade e das exigências afirmou a importância crescente e fundamental do gerenciamento eficaz.

Um ponto central na evolução do conceito militar de estratégia para o conceito contemporâneo é a multiplicação de objetivos a serem atingidos pela organização para atender diferenciados stakeholders. Se a mudança de um objetivo único para diversos gera a necessidade de uma estratégia muito mais complexa, a sua execução torna-se mais ainda. Daí os inúmeros fracassos organizacionais a despeito da qualidade da sua formulação estratégica (Canhada \& Rese, 2011).

A administração estratégica busca superar uma das principais fraquezas apresentadas pelo planejamento estratégico: a dificuldade na implementação das estratégias ou ações estabelecidas nesse planejamento, além de trazer uma visão sistêmica das organizações como um todo (Mintzberg, Ahlstrand \& Lampel, 2010). Através de uma compreensão ampla, que não se baseia apenas em análises quantitativas e deterministas, evolui-se do planejamento estratégico limitado para uma gestão estratégica organizacional onde a for- 
mulação estratégica tem uma abrangência maior (Mintzberg, 2006). Coloca-se em questão se a prevalência de modelos que defendem que a estratégia é primeiro formulada e depois implementada em uma "esteira de produção" (Mintzberg, 2006, p.17) ainda é válida ou se na atualidade da gestão estratégica formular e implementar são processos interligados e inseparáveis.

\subsection{Planejamento - posicionamento - van- tagem competitiva}

O ciclo estratégico típico que tantas organizações seguem pode travar a agilidade das mesmas para reagir às mudanças, ameaças e oportunidades. Ao abordar as questões do ambiente organizacional, é encontrado em Porter (1996a) elevada ênfase para o ambiente externo composto de forças macroambientais e microambientais e transmite a ideia de que a partir de uma análise cuidadosa e correta, o alcance dos objetivos torna-se factível, pois restará claro como a organização irá competir, formulando sua estratégia e definindo seu posicionamento. Porter (1996a) defende que sempre há uma estratégia, explícita ou não, e que quando essa não parte de um processo explícito de formulação, estruturado, raramente tem bons resultados. A afirmação mostra-se coerente na medida em que se torna difícil implementar algo que não está explícito. Sob outro aspecto, a visão de Porter (1996a) é criticada, pois transmite a ideia de que apenas seguindo uma metodologia básica e estruturada, chega-se a um resultado certo e positivo, o que não é a realidade de inúmeras organizações. Porter (1996b) reforça uma preocupação maior com o planejamento do que com a execução. Mesmo assim, o autor deixa claro que para a obtenção de vantagem competitiva são necessárias ações específicas que precisam ser executadas com foco e determinação, não sendo mero desdobramento do planejamento estratégico.

Contrapondo-se aos pressupostos de estratégia porterianos, podem ser citadas algumas propostas de estratégia como o RBV-
Resources Based View of the Firm (Wernerfelt,1984), que destaca as competências internas, ou ter uma visão do mercado não somente como um ambiente competitivo, mas também colaborativo, Coopetição (Nalebuff \& Brandenburger, 1996), ou, ainda, na forma inovadora de estratégia que propõe interligar formulação e execução do Oceano Azul (Kim \& Mauborgne, 2005), trazem à tona fatores que são importantes para uma boa execução estratégica. Em Oceano Azul, os autores afirmam que três princípios, podem mitigar o insucesso da estratégia: envolvimento, explicação e clareza das expectativas. Com isso, os membros da organização terão ciência dos porquês das decisões, os mesmos também se envolverão nas decisões que os afetam e por fim saberão quais os critérios pelos quais serão medidos e a quem pertence cada atribuição com as respectivas consequências.

Destaca-se ainda o modelo de Balanced Scorecard - BSC (Kaplan \& Norton, 2006) cuja premissa é alinhar, interligando o desenvolvimento e formulação das estratégias e sua efetiva execução com resultados. Kaplan e Norton (2006) identificam alguns problemas para o sucesso estratégico como a não "tradução" da visão, a desvinculação de estratégia e indivíduos, definições estratégicas desalinhadas e a alocação dos recursos necessários e a falta de acompanhamento e feedback do processo de execução e resultados. Nesse contexto é que o BSC foi construído como um modelo que viabiliza e apoia o gerenciamento da execução da estratégia e não apenas como um sistema de medição e controle.

Salienta-se que seja qual for o método ou linha de pensamento utilizada para deliberar as escolhas estratégicas, todas ocorrerão por meio de pessoas, com toda a imprecisão da natureza humana, com ênfase especial no papel do gestor e seus modelos mentais. Estará nas mãos do gestor (líder) a reponsabilidade de traduzir a estratégia por meio de uma linguagem que todos entendam com definição de prioridades e delimitação de objetivos, envolvendo toda a organização, cuidar para que 
o conteúdo não degrade ao longo da cadeia e manter a comunicação contínua. Para Hrebiniak (2013) o líder é um fator que afeta fortemente a execução, pois é quem define a forma como as organizações respondem a todos os desafios precedentes da execução e que deve motivar o sentimento de pertencimento. Neste sentido, Mintzberg (2006, p.93) afirma: "desenvolver a fé na capacidade da organização de atingir suas metas, motivá-la a fazer isso, focar sua atenção o suficiente para internalizar novas aptidões - esse é o real desafio para a alta gerência", ou seja, da liderança.

\subsection{Execução estratégica}

$\mathrm{Na}$ literatura destacam-se fatores apontados como direcionadores de sucesso ou insucesso da implantação estratégica. Cândido e Santos (2019) estimam que as falhas nas execuções estratégicas podem chegar até a $70 \%$, sendo consequência de uma cadeia de fatores organizacionais interrelacionados. Os autores elencam, por meio de um estudo de caso único, 65 fatores categorizados em liderança, tempo, resistência e envolvimento das equipes, cultura organizacional, estrutura / recursos, eventos externos, entre outras categorias. Na categoria comunicação, os autores atribuem 15 fatores que impactam na execução estratégica. É a categoria com maior quantidade de itens.

Nessa linha de pesquisa de detectar o que impacta a estratégia, Beer e Eisenstat (2000) reforçam o papel do líder como fator central para mitigar os "assassinos da estratégia”. Mintzberg et al. (2010, p.86 p.119) corroboram e ampliam esse pensamento ao não destacarem só o líder e falarem de pessoas, quando afirmam que: "são as pessoas que fazem as empresas ter sucesso ou fracassar", e que "uma estratégia bem-sucedida é aquela em que as pessoas comprometidas infundem energia: elas a tornam boa ao torná-la real". Crittenden e Crittenden (2008) denominam a implementação estratégica como "pedra angular" e destacam que sem alinhamento e compartilhamento de informações generali- zado o sucesso se torna improvável. Os autores delimitam que os problemas de execução estratégica giram em torno de estrutura e habilidades gerenciais e sugerem a utilização de programas de aprendizagem e melhoria contínua, sistemas de apoio, monitoramento, alocação de recursos e interação. Em alinhamento às afirmações de Crittenden e Crittenden (2008), tem-se em Hrebiniak (2008, p.68 p.167) um diagnóstico similar ao afirmar que: "a estrutura empresarial deve refletir a natureza da estratégia de negócios e ser guiada principalmente por ela. [...] a estratégia afeta a estrutura $[\ldots]$ ".."

Cocks (2010) nomeia causas das "avarias" na implementação estratégica, os fatores ligados às competências, a processos e atividades para efetivar a estratégias, as competências críticas, enfatizando a importância da atenção ao detalhe para enfrentar a complexidade, e a importância de "digerir" as atividades, simplificando-as e comunicando-as eficazmente. Cocks (2010) prioriza o foco sem "modismos", simplicidade e clareza na comunicação da estratégia, além atitudes realistas em relação aos objetivos propostos e os recursos disponíveis. $\mathrm{O}$ autor ressalta o papel do líder para disseminar, com a clareza necessária, a escolha das pessoas certas para vencer os "bolsões de resistência". Esses "silos", assim como as questões que envolvem comunicação e cultura organizacionais, também são apontadas por Galpin (2018) que indica esses fatores como chave para o sucesso da execução estratégica e afirma que a cultura pode inviabilizar as melhores intenções gerenciais.

Nas pesquisas sobre execução estratégica realizados por Bossidy e Charan (2005), destacam-se os fatores: disciplina, o envolvimento direto e um conjunto de características e comportamentos, não sendo a execução somente tática e sim uma atividade complexa repleta de fatores a observar.

Enquanto pesquisa de campo, o presente estudo está baseado nos trabalhos desenvolvidos por Hrebiniak (2006, 2008 e 2013) ampliando o questionário aplicado em suas 
pesquisas com o intuito de identificar os obstáculos à execução estratégica eficaz. A possibilidade de ampliar a abordagem de Hrebiniak (2008 e 2013) na realidade organizacional de uma corporação pública representativa brasileira, mapeando seus fatores de impacto, nos motivou.

O autor discorre que é preciso compreender que a elaboração e a implementação da estratégia são interdependentes e que a execução é essencial para o sucesso do plano estratégico. Ainda acrescenta que: "a execução exige uma cultura de realização, disciplina e pertença" (Hrebiniak, 2008, p.43). No Quadro 1 é apresentado um resumo das pesquisas de Hrebiniak (2006) que foram relizadas em dois momentos distintos, acrescidas dos resultados provenientes deste estudo. Os resultados obtidos por Hrebiniak (2006) elencam fatores de impacto já apontados neste estudo, e outros a abordar. Um desses fatores não está explícito no Quadro 1, mas permeia o tema: revisão estratégica. A verificação para a realização dos ajustes necessários, deve ser maior do que verificar se os indicadores econômico-financeiros estão sendo alcançados, já que os fatores críticos de sucesso que determinam a qualidade dos resultados, nem sempre são mensuráveis (Mintzberg, 2006). A avaliação, que deve ser cíclica e continua, perguntas devem ser retomadas verificando se o resultado obtido até aquele momento confirma ou rebate as suposições iniciais que embasaram a estratégia (Mintzberg, 2006), afinal, gestão estratégica organizacional é um processo contínuo, sem fim, enquanto a organização existir. Mankins e Steele (2005) afirmam que "menos de $15 \%$ das empresas costumam monitorar o desempenho pretendido em relação ao desempenho verificado". Para os autores, essa falta de introspecção leva as empresas a ignorarem facilmente os planos mal sucedidos, facilitando os equívocos em relação à próxima estratégia a se seguir.

Nas pesquisas de Hrebiniak (2013) surge esse mesmo diagnóstico quando os gerentes afirmam sobre a importância do controle e das revisões da estratégia para proporcionar a adaptação organizacional. Raffoni (2003) também diagnosticou a necessidade de frequente acompanhamento das condições e recursos necessários para a execução estratégica e os consequentes ajustes e correções para a sustentabilidade dos propósitos estratégicos, denominando como um dos "Três Fatores-Chave para uma Execução Efetiva". Mintzberg (2006) e Cocks (2010) também afirmam que o processo de reavaliação não ocorre frequentemente, e isso coloca em risco todo o posicionamento estratégico; além de afirmarem que o sucesso organizacional requer revisão constante, inter-relação entre o formular e o executar estratégia e adaptação rápida e flexível. Bossidy e Charan (2005, p.189) afirmam que a revisão estratégica "é o principal Mecanismo Operacional Social do processo de estratégia. É o penúltimo campo para testar e validar a estratégia - a última chance $[. .$.$] ". Essas revisões são essenciais$ para o sucesso da execução estratégica, pois permitem o diagnóstico real da distância entre o desejado e a realidade reforçando os métodos de execução e assegurando um mecanismo de correção que permite a aprendizagem e a adaptação organizacionais, dissecando os problemas e compreendendo as razões de um desempenho indesejado (Hrebiniak, 2013). O gestor precisa evitar lapsos de percepção, ou seja, uma percepção tardia dos movimentos internos e externos da organização. Porter (2009, p.515) ressalta que "é difícil saber o que está realmente acontecendo". Decisões estratégicas imprescindem de informação que, em diversas situações, não chegam ou são distorcidas. Ainda pior, o conhecimento de fatos acontece depois de consumado. A questão a avaliar é qual o ponto "ótimo" de informações, já que são necessárias, mas em quantidade insuficiente não subsidiam as decisões e, em excesso, propiciam a confusão. Galpin (2018) acrescenta a importância de revisar, também a necessidade de comemorar as vitórias das etapas menores que compõem o todo. 
Outra questão fundamental trata do alinhamento que é apontada por Mintzberg et al. (2010) e por Heide, Gronhaug e Johannessen (2002) como um dos pontos focais para o sucesso das estratégias, a comunicação eficiente entre os diversos atores na complexidade organizacional para mitigar a falta de interação. Ritson, Johansen e Osborne (2012) corroboram essas conclusões ao afirmar que é um atributo essencial o alinhamento contínuo para a "entrega" bem-sucedida. Chega-se, assim, a um dos problemas estratégicos cruciais: a comunicação. Esse diagnóstico também apontado por Hrebiniak (2013) que detecta em suas pesquisas que compartilhamento deficiente ou inadequado de informações, entre as pessoas ou unidades de negócios responsáveis pela execução estratégica, são um dos grandes pontos de atenção e que as responsabilidades precisam ficar claras ao passo que as estratégias necessitam de cooperação, coordenação e comunicação, já que percepções e/ ou pressupostos divergentes geram conflitos. Acrescenta que compartilhar conhecimento e informações para conseguir coordenação entre as áreas organizacionais é vital para um possível sucesso estratégico com o aumento de flexibilidade e da capacidade de reação aos obstáculos da execução (Hrebiniak, 2013). Uma estratégia vaga ou deficiente não tem como ser executada.

Devlin (1989) destaca os problemas para a execução estratégica que se relacionam com as demais pesquisas citadas como: fragilidade na comunicação, falta de recursos, rotatividade elevada dos gestores responsáveis, tempo de execução elevado, não envolvimento das equipes, inclusive de pessoas-chave para o processo estratégico, sistemas de informação inadequados, falta de previsibilidade nas mudanças do ambiente externo, estrutura organizacional rígida e não adaptativa, conflitos organizacionais e incapacitação dos líderes.

Nesse contexto podemos destacar também stakeholders significativos na dinâmica planejar/ executar/ revisar: o conselho de administração. A despeito de não ser uma unanimidade o consenso da importância dos Conselhos de Administração para a execução estratégica (Baptista, 2013), há a indicação de que a interferência do conselho, aprovando e rejeitando propostas estratégicas, contribui para a monitoração eficaz da execução, identificando seus desvios e promovendo alinhamento. Baptista (2013, p.28) traz em suas pesquisas a ideia de que aumenta a certeza de o monitoramento da execução estratégica também ser um atributo do Conselho de Administração, já que "[...] promover a implementação eficaz das estratégias corporativas é uma questão central para as empresas porque, dentre outras razões, as falhas de implementação estratégica destroem valor".

Como então fazer funcionar? As pesquisas aqui citadas, sejam as mais recentes ou não, convergem a pontos como a necessidade de alinhamento, a importância das pessoas, o papel do gestor e a necessidade de estrutura. De modo mais pragmático, alguns autores buscam a construção de modelos, difíceis de construir, que têm como objetivo trazer alguma estrutura prática na busca da solução dos problemas estratégicos ligados à execução.

Kich, Pereira, Emmendoerfer e dos Santos (2008, p.123) utilizam uma afirmação forte, mas infelizmente real em algumas organizações: "o problema surge quando chega o momento de agir e colocar as estratégias definidas em prática, ou seja, o momento de implementar o plano estratégico, quando na maioria das vezes ele começa a morrer". Galpin (2018) aponta que a execução estratégica precisa ser priorizada na gestão.

Identificam-se assim linhas de pensamento diferentes, mas que convergem para o diagnóstico dos problemas estratégicos, que também podem ser interpretados como oportunidades para o alcance de uma vantagem competitiva se forem compreendidos, gerenciados e superados (Hrebiniak, 2013). Porém, a fórmula exata para a solução dos problemas estratégicos ainda não se apresenta. Neilson, Martin e Powers (2008, p.1) ao afirmarem 
que: "a estratégia brilhante pode colocá-lo no mapa competitivo, mas só a sólida execução mantê-lo lá" e a pergunta levantada por Slater, Olson e Hult (2010, p.22): "será que temos a arquitetura certa para a implementação da estratégia eficaz?" é tão importante quanto: "qual é a estratégia certa?"

\section{Método}

Foi realizado um levantamento bibliográfico utilizando como termos-chave em português e inglês: implementação, implementação estratégica, execução e execução estratégica. Por meio do Portal de Peródicos Capes, foram acessadas as principais bases em bancos de dados acadêmicos identificando na literatura os principais autores preocupados com a execução estratégica e seus fatores. A pesquisa se baseia em um estudo de caso com caráter descritivo por meio de análises quantitativas, construído com o envio de 1020 questionários com retorno de 380 , devidamente precedidos pelo atendimento aos quesitos do Comitê de Ética - PUC/SP, via Plataforma Brasil, e preconizados por meio da Resolução CNS 466/12. O envio e a coleta de respostas ocorreu de 31/03/2016 a 03/05/2016 e todos os respondentes concordaram com o TCLE (Termo de Consentimento Livre e Esclarecido). Somado aos questionários, também foram utilizados relatórios anuais públicos da organização objeto de estudo.

Yin $(2001$, p.18) afirma que o uso de estudos de caso é indicado para estudos organizacionais e gerenciais, nos quais se busca responder a questões sobre "como" e "por quê" e se "examinam acontecimentos contemporâneos, mas quando não se podem manipular comportamentos relevantes". Ainda conforme Yin (2001, p.24) a mais importante aplicação para os estudos de caso "é explicar os vínculos causais em intervenções da vida real que são complexas demais para as estratégias experimentais".

A empresa estudada atua no mercado financeiro como banco múltiplo com representação em todo o território nacional e, também, internacionalmente. É uma empresa $100 \%$ pública com 159 anos (2020) de existência. Atua fortemente como instrumento do Governo Federal para a realização de políticas públicas, fomento habitacional e de infraestrutura das cidades e programas sociais, além de ser patrocinadora de atividades em áreas diversas. É detentora de uma das marcas mais valiosas no Brasil e na América do Sul.

A referida organização se utiliza de ferramentas estratégicas, entre elas o BSC Balanced Scorecard desde 2011, tem em sua estrutura equipes focadas no planejamento e execução estratégicas com uma área Matriz com esse objetivo exclusivo, e utiliza como ferramenta para alinhar a avaliação de desempenho de todas as suas áreas às definições estratégicas inseridas em seu Mapa, um sistema de acompanhamento diário com avaliação semestral e traz em suas cartilhas que o objetivo principal, além desse alinhamento, a busca pela a sustentabilidade dos resultados com a qualificação dos negócios. O sistema apresenta três pilares principais: Sustentabilidade, Resultado Financeiro e Produção (onde encontra-se a especificação de que o que se busca é o alinhamento entre planejamento e execução diária dos negócios).

A escolha da organização foi dada pela sua representatividade, tamanho, diversidade de atuação e, por consequência, sua grande complexidade. Os entrevistados foram aqueles diretamente ligadas à gestão estratégica da organização.

Ao questionário elaborado, composto inicialmente por seis perguntas, baseado na pesquisa de Hrebiniak (2008), foram acrescidas três perguntas, alinhadas aos objetivos específicos desta pesquisa. A ferramenta eletrônica Survey Monkey®. foi utilizada, o que permitiu distribuição e acessibilidade eficazes aos respondentes.

A instituição tem aproximadamente 97.000 empregados (2016), dos quais 8.639 são ocupantes de cargos em gestão. A tabela 1 apresenta resumidamente a população, a amostra e o número de respondentes, segmentados por matriz, filiais e rede. 


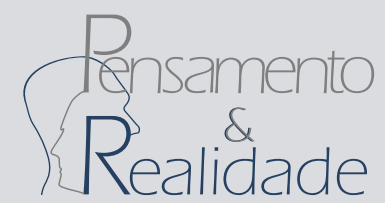

Tabela 1. Distribuição de Questionários

\begin{tabular}{|l|l|l|l|l|l|l|}
\hline & POPULAÇÃO & AMOSTRA & ENVIADAS & DEVOLV. & RESPOSTAS & $\%$ RESPOSTAS \\
\hline TOTAL & 8639 & 1000 & 1020 & 16 & 380 & 37,25 \\
\hline MATRIZ & 1219 & 100 & 103 & 4 & 42 & 40,78 \\
\hline FILIAIS & 3351 & 250 & 251 & 1 & 108 & 43,03 \\
\hline REDE & 4069 & 650 & 666 & 11 & 230 & 34,53 \\
\hline
\end{tabular}

Fonte: Elaborados pelos autores

Atendendo aos critérios de confiabilidade e validade, foi calculada a amostra representativa dentro da população de 8639 gestores definindo uma margem de erro de $5 \%$ e um nível de confiança de $95 \%$ chegando a uma amostra mínima necessária de 368 respondentes. A tabulação das respostas ocorreu com o prévio estabelecimento de palavras-chave nas questões abertas para identificar o padrão existente. Nesses casos, foi utilizado o princípio de análise Dummy quando os dados são classificados conforme características qualitativas padrão e são definidas variáveis binárias para as respostas possibilitando que elas fossem aproveitadas para a análise estatística. Nas questões fechadas a escala Likert foi utilizada, e as respostas classificadas conforme a frequência da sua ocorrência. Os dados foram tratados utilizando análise fatorial exploratória, que segundo Figueiredo Filho e Silva Júnior (2010), é uma análise que estabelece a relação entre um conjunto de variáveis identificando padrões de correlação, auxiliando nas pesquisas em ciências sociais ao buscar identificar e medir variáveis que não podem ser medidas diretamente, mas nas quais é possível identificar os componentes principais que podem ser agrupados em fatores (Field, 2009). Utilizado para as análises estatísticas o software ${ }^{4}$ SPSS Statistics com validação de dados por meio do KMO e o teste de esfericidade de Bartlett e a rotação varimax. Como a quantidade de dados sob análise é significativa, a quantidade padrão do SPSS de iterações máximas foi alterada para convergência de vinte e cinco para trinta (Field, 2009). As análises iniciaram com trinta e quatro variáveis que apresentaram comunalidade superior a 0,5, KMO de 0,793, gerando dez fatores que explicavam $67,096 \%$ dos dados. Ao longo das rodadas de análise, para trazer maior nível de confiabilidade, excluiram-se variáveis que: apresentaram MSA inferior a 0,5 , possuíam cargas fatoriais inferiores a 0,4, tinham baixo índice de confiabilidade, compunham fatores isoladamente e aquelas que não possibilitaram calcular o Alpha de Cronbach.

Após a realização da análise fatorial, calculou-se os Alphas de Cronbach, que variam de 0 a 1 para cada fator, de modo a verificar a confiabilidade da escala que, segundo Field (2009), entende-se quando o resultado fica entre 0,7 a 0,8 , sendo a confiabilidade considerada como razoável. Abaixo de 0,7 a 0,6 pode ser considerada como baixa a consistência interna da escala ou fraca, e entre 0,8 e 0,9 são considerados bons. Tem-se como exceção estudos de Ciências Sociais, como é o caso da presente pesquisa, que podem ser aceitos Alphas próximos a 0,60. Após cinco rodadas de análise, obteve-se vinte e oito variáveis com maior significância, distribuídas em seis fatores com KMO de 0,808 , e que serão abordadas em relação aos fatores que impactam no presente estudo. Os resultados estão demonstrados nas Tabelas 2,3,4,5,6 e Figura 1. 
Tabela 2. Comunalidades

\begin{tabular}{|c|c|c|}
\hline & Initial & Extraction \\
\hline Vaga & 1,000 &, 752 \\
\hline Sem diretrizes & 1,000 &, 787 \\
\hline Sem recursos financeiros & 1,000 & ,600 \\
\hline Conflitos de poder & 1,000 & ,665 \\
\hline Sem aprovação & 1,000 & ,616 \\
\hline Sem suporte & 1,000 &, 598 \\
\hline Sem pertencimento & 1,000 & ,690 \\
\hline Sem incentivos & 1,000 & ,684 \\
\hline Sem compartilhamento & 1,000 & ,742 \\
\hline Sem comunicação & 1,000 &, 721 \\
\hline Sem compreensão & 1,000 & ,656 \\
\hline Incapacidade de gerenciar mudanças & 1,000 & ,622 \\
\hline Equipes multifuncionais & 1,000 & ,613 \\
\hline Comunicação informal & 1,000 & ,697 \\
\hline Inteadores formais & 1,000 & 679 \\
\hline Estrutura matricial & 1,000 & 609 \\
\hline Relutância da equipe & 1,000 &, 588 \\
\hline Informações não confiáveis & 1,000 & ,561 \\
\hline Relutância dos gerentes & 1,000 &, 677 \\
\hline Sem informações & 1,000 &, 773 \\
\hline Incompreensão da utilidade & 1,000 & ,642 \\
\hline Demora nas decisões & 1,000 & ,646 \\
\hline Incompreensão de contribuições & 1,000 & ,689 \\
\hline Demora a respostas e aos problemas & 1,000 & ,625 \\
\hline Lentidão de reação & 1,000 &, 702 \\
\hline Burocracia & 1,000 & ,759 \\
\hline Fazer política & 1,000 & ,648 \\
\hline Desaparecimento de informações & 1,000 &, 588 \\
\hline Refazendo & 1,000 & ,636 \\
\hline Incerteza sobre a estratégia & 1,000 & 699 \\
\hline Conhecimento BSC & 1,000 & ,641 \\
\hline Importância das ferramentas & 1,000 & ,556 \\
\hline
\end{tabular}

Fonte: SPSS 


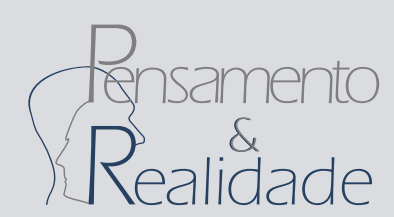

Tabela 3 Eigenvalues - Autovalores

\begin{tabular}{|c|c|c|c|c|c|c|c|c|c|}
\hline \multirow[b]{3}{*}{ Component } & \multicolumn{9}{|c|}{ Total Variance Explained } \\
\hline & \multicolumn{3}{|c|}{ Initial Eigenvalues } & \multicolumn{3}{|c|}{ Extraction Sums of Squared Loadings } & \multicolumn{3}{|c|}{ Rotation Sums of Squared Loadings } \\
\hline & Total & $\%$ of Variance & Cumulative $\%$ & Total & $\%$ of Variance & Cumulative $\%$ & Total & $\%$ of Variance & Cumulative \% \\
\hline 1 & 7,259 & 22,684 & 22,684 & 7,259 & 22,684 & 22,684 & 6,350 & 19,845 & 19,845 \\
\hline 2 & 3,589 & 11,217 & 33,901 & 3,589 & 11,217 & 33,901 & 2,660 & 8,311 & 28,156 \\
\hline 3 & 2,154 & 6,732 & 40,633 & 2,154 & 6,732 & 40,633 & 2,266 & 7,081 & 35,237 \\
\hline 4 & 1,910 & 5,968 & 46,601 & 1,910 & 5,968 & 46,601 & 2,260 & 7,063 & 42,300 \\
\hline 5 & 1,519 & 4,748 & 51,349 & 1,519 & 4,748 & 51,349 & 1,678 & 5,245 & 47,544 \\
\hline 6 & 1,420 & 4,439 & 55,788 & 1,420 & 4,439 & 55,788 & 1,600 & 4,999 & 52,543 \\
\hline 7 & 1,170 & 3,656 & 59,445 & 1,170 & 3,656 & 59,445 & 1,553 & 4,853 & 57,396 \\
\hline 8 & 1,116 & 3,487 & 62,932 & 1,116 & 3,487 & 62,932 & 1,424 & 4,450 & 61,846 \\
\hline 9 & 1,024 & 3,199 & 66,131 & 1,024 & 3,199 & 66,131 & 1,371 & 4,285 & 66,131 \\
\hline 10 & ,944 & 2,951 & 69,082 & & & & & & \\
\hline 11 & ,885 & 2,766 & 71,847 & & & & & & \\
\hline 12 & ,806 & 2,520 & 74,367 & & & & & & \\
\hline 13 & ,713 & 2,228 & 76,595 & & & & & & \\
\hline 14 & ,655 & 2,046 & 78,641 & & & & & & \\
\hline 15 & ,622 & 1,943 & 80,584 & & & & & & \\
\hline 16 & 607 & 1,897 & 82,481 & & & & & & \\
\hline 17 &, 555 & 1,733 & 84,214 & & & & & & \\
\hline 18 &, 519 & 1,621 & 85,835 & & & & & & \\
\hline 19 & ,492 & 1,538 & 87,372 & & & & & & \\
\hline 20 & ,461 & 1,442 & 88,814 & & & & & & \\
\hline 21 & ,444 & 1,388 & 90,202 & & & & & & \\
\hline 22 & ,422 & 1,318 & 91,520 & & & & & & \\
\hline 23 & ,388 & 1,213 & 92,733 & & & & & & \\
\hline 24 & 372 & 1,162 & 93,895 & & & & & & \\
\hline 25 & 340 & 1,062 & 94,957 & & & & & & \\
\hline 26 & ,331 & 1,034 & 95,991 & & & & & & \\
\hline 27 & 287 & 896 & 96,887 & & & & & & \\
\hline 28 & , 255 & ,798 & 97,685 & & & & & & \\
\hline 29 & ,232 & ,726 & 98,410 & & & & & & \\
\hline 30 & 208 & 650 & 99,061 & & & & & & \\
\hline 31 & , 161 &, 504 & 99,565 & & & & & & \\
\hline 32 & 139 & .435 & 100,000 & & & & & & \\
\hline
\end{tabular}

Fonte: SPSS 


\begin{tabular}{|c|c|c|c|c|c|c|c|c|c|}
\hline \multicolumn{10}{|c|}{ Rotated Component Matrix ${ }^{a}$} \\
\hline & \multicolumn{9}{|c|}{ Component } \\
\hline & 1 & 2 & 3 & 4 & 5 & 6 & 7 & 8 & 9 \\
\hline semcomunicação & 0,822 & & & & & & & & \\
\hline sempertencimento & 0,800 & & & & & & & & \\
\hline semcompartilhamento & 0,796 & & & & & & & & \\
\hline conflitosdepoder & 0,794 & & & & & & & & \\
\hline semincentivos & 0,794 & & & & & & & & \\
\hline semsuporte & 0,739 & & & & & & & & \\
\hline incapacidadedegerenciarmudanças & 0,732 & & & & & & & & \\
\hline semcompreensão & 0,729 & & & & & & & & \\
\hline vaga & 0,631 & & & & & 0,586 & & & \\
\hline semrecursosfinanceiros & 0,588 & & & & & & & & \\
\hline semaprovação & 0,487 & & & & & & & & \\
\hline informaçõesnãoconfiaveis & & 0,711 & & & & & & & \\
\hline relutanciadaequipe & & 0,692 & & & & & & & \\
\hline relutanciadosgerentes & & 0,689 & & & & & & & \\
\hline seminformações & & 0,685 & & & & & & & 0,420 \\
\hline incompreensãodautilidade & & 0,665 & & & & & & & \\
\hline integradoresformais & & & 0,760 & & & & & & \\
\hline equipesmultifuncionais & & & 0,750 & & & & & & \\
\hline estruturamatricial & & & 0,668 & & & & & & \\
\hline comunicaçãoinformal & & & 0,616 & & & & & & $-0,500$ \\
\hline refazendo & & & & 0,769 & & & & & \\
\hline incertezasobreaestratégia & & & & 0,741 & & & & & \\
\hline fazerpolitica & & & & 0,672 & & & & & \\
\hline desaparecimentodeinformações & & & & 0,634 & & & & & \\
\hline lentidãodereação & & & & & 0,740 & & & & \\
\hline demoranasdecisões & & & & & 0,717 & & & & \\
\hline semdiretrizes & 0,576 & & & & & 0,634 & & & \\
\hline conhecimentobsc & & & & & & & 0,753 & & \\
\hline importanciadasferramentas & & & & & & & 0,688 & & \\
\hline burocracia & & & & & & & & 0,845 & \\
\hline demoraarespostasaosproblemas & & & & & & & & 0,512 & 0,442 \\
\hline incompreensãodecontribuições & & & & & & & & & 0,665 \\
\hline
\end{tabular}

Fonte: SPSS 


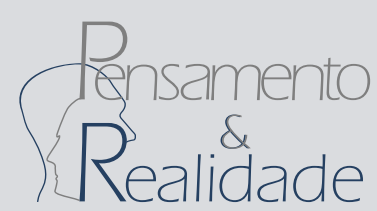

Tabela 5. Resultado KMO e Bartlett's

\begin{tabular}{|l|l|l|}
\hline Kaiser-Meyer-Olkin Measure of Sampling Adequacy. &, 808 \\
\hline \multirow{3}{*}{ Bartlett's Test of Sphericity } & Approx. Chi-Square & 1960,406 \\
\cline { 2 - 3 } & df & 496 \\
\cline { 2 - 3 } & Sig. &, 000 \\
\hline
\end{tabular}

Fonte: SPSS

Tabela 6. Análise Fatorial e Análise de Confiabilidade

\begin{tabular}{|c|c|c|c|c|c|c|c|c|c|c|c|}
\hline \multirow[t]{2}{*}{ Rotated Component Matrixa } & \multirow[t]{2}{*}{ Communalities } & \multicolumn{9}{|c|}{ Component } & Alpha de Cronbach \\
\hline & & Ty & 2 & 3 & 4 & 5 & 6 & 7 & 8 & 9 & \\
\hline 1 semcomunicação & 0,721 & $10.02 \%$ & 0,114 & & & & & & & $0,109 y$ & \\
\hline 2 sempertencimento & $0,69\rangle^{\prime}$ & 1060 & & 0,176 & & & & 0,103 & & & \\
\hline 3 semcompartilhamento & $0,742 Y$ & $1095 /$ & 0,184 & & & & $-0,118$ & $-0,201$ & & & \\
\hline 4 conflitosdepoder & $0,6655^{\prime}$ & 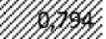 & & & & & & $-0,142$ & & & \\
\hline 5 semincentivos & $0,684 \sum$ & 1094 & & & & & $-0,127$ & & & & \\
\hline 6 semsuporte & 0,598 & 139 & & 0,180 & & & & & 0,102 & & 938 \\
\hline 7 incapacidadedegerenciarmudar & $0,622 z^{\prime}$ & On将 & & & 0,151 & & 0,209 & & & & \\
\hline 8 semcompreensão & 0,656 & 195 & $-0,118$ & & & 0,164 & 0,216 & 0,138 & & $-0,107 Y^{\prime}$ & \\
\hline 9 vaga & $0,752 y$ & 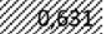 & & & & & 0,586 & & & & \\
\hline 10 semrecursosfinanceiros & $0,6 Y^{\prime}$ & 08 & 0,164 & & & 0,174 & 0,369 & 0,111 & $-0,164$ & & \\
\hline 11 semaprovação & 0,616 & 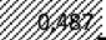 & 0,270 & 0,228 & & 0,180 & 0,384 & $-0,205$ & 0,166 & & \\
\hline 12 informaçõesnãoconfiaveis & 0,561 & & 0,711 & & & & & & 0,162 & & \\
\hline 13 relutanciadaequipe & 0,588 & 0,154 & 0,692 & & 0,152 & & 0,111 & 0,116 & & $-0,171$ & \\
\hline 14 relutanciadosgerentes & 0,677 & & 0,689 & & & & 0,294 & $-0,122$ & 0,262 & $-0,153$ & 0,794 \\
\hline 15 seminformações & 0,773 & & 0,685 & & & 0,241 & $-0,117$ & & $-0,219$ & 0,420 & \\
\hline 16 incompreensãodautilidade & 0,642 & & 0,665 & $-0,228$ & & & $-0,221$ & 0,147 & $-0,116$ & 0,237 & \\
\hline 17 integradoresformais & 0,679 & 0,225 & & $0 ; 760$ & & & & & $-0,179$ & & \\
\hline 18 equipesmultifuncionais & 0,613 & 0,180 & & 0750 & & & & & & & \\
\hline 19 estruturamatricial & 0,609 & & $-0,134$ & 0,668 & & $-0,197$ & & $-0,215$ & 0,144 & 0,190 & \\
\hline 20 comunicaçãoinformal & 0,697 & & & $6+6$ & $-0,115$ & 0,119 & & 0,172 & & $-0,500$ & \\
\hline 21 refazendo & 0,636 & & & & 0,769 & & & & & 0,154 & \\
\hline 22 incertezasobreaestratégia & 0,699 & & & & 0,741 & & 0,196 & 0,256 & 0,186 & & 55 \\
\hline 23 fazerpolitica & 0,648 & & 0,126 & & 0,672 & 0,352 & $-0,205$ & & & & \\
\hline 24 desaparecimentodeinformaçõe & 0,588 & 0,181 & 0,179 & $-0,125$ & 0,634 & 0,134 & $-0,150$ & & 0,130 & 0,203 & \\
\hline 25 lentidãodereação & 0,702 & & & & 0,241 & 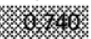 & 0,281 & & & & \\
\hline 26 demoranasdecisões & 0,646 & & & $-0,100$ & & 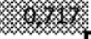 & $-0,159$ & 0,136 & 0,245 & 0,106 & \\
\hline 27 semdiretrizes & 0,787 & 0,576 & & & & & 0,634 & $-0,128$ & & 0,143 & \\
\hline 28 conhecimentobsc & 0,641 & & & $-0,131$ & & $-0,173$ & $-0,126$ & 0,753 & & & \\
\hline 29 importanciadasferramentas & 0,556 & & & & & 0,236 & & 0,688 & & & 0,387 \\
\hline 30 burocracia & 0,759 & & & & 0,149 & 0,116 & & & 0,845 & & \\
\hline 31 demoraarespostasaosproblema & 0,625 & 0,182 & 0,124 & & 0,106 & 0,313 & & & 0,512 & 0,442 & 0,592 \\
\hline 32 incompreensãodecontribuições & 0,689 & & & & 0,228 & 0,192 & 0,181 & 0,309 & 0,130 & 0,665 & \\
\hline Eingenvalue & & 7,259 & 3,589 & 2,154 & 1,91 & 1,519 & 1,42 & 1,17 & 1,116 & 1,024 & \\
\hline \% VariEancia Extraida & $66,131 \%$ & $19,845 \%$ & $8,311 \%$ & $7,081 \%$ & $7,063 \%$ & $5,245 \%$ & $4,999 \%$ & $4,853 \%$ & $4,450 \%$ & $4,285 \%$ & \\
\hline
\end{tabular}

Fonte: Elaborada pelos autores 
Figura 1. Diagrama de Declividade

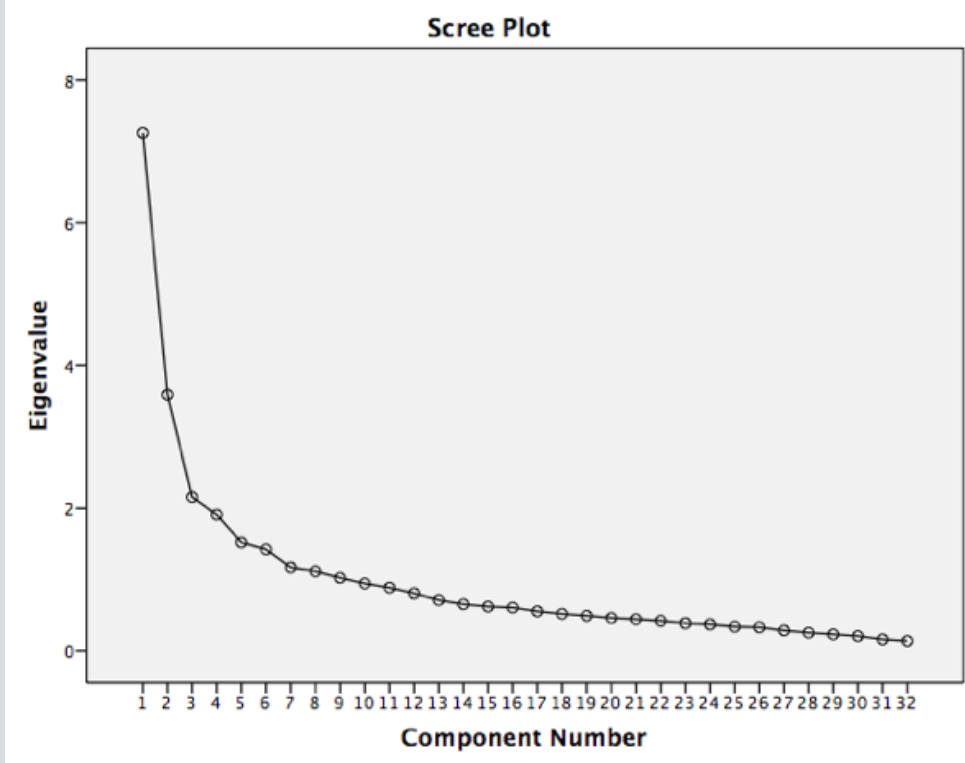

Fonte: SPSS

Nomearam-se os seis fatores pela sua ade- que a compreensão dos resultados seja mais rência às variáveis que os compõem, de modo efetiva conforme demonstrado na Tabela 7 .

Tabela 7. Nomeação dos Fatores

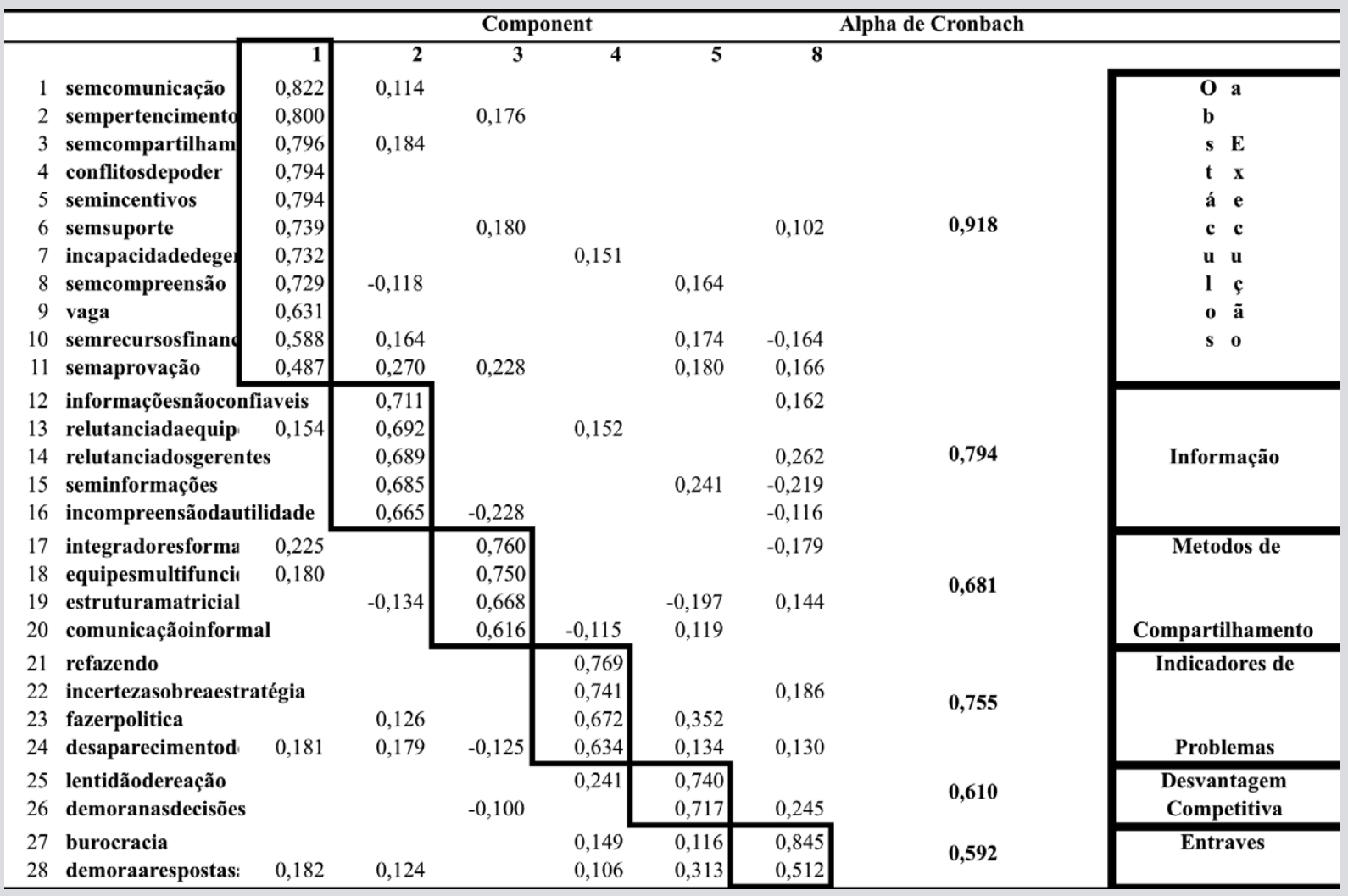

Fonte: Elaborada pelos autores 


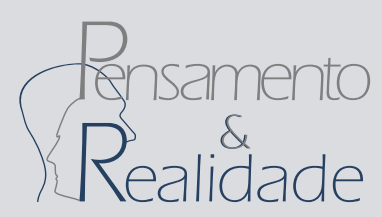

\section{Resultados}

Um dos principais pontos debatidos neste estudo é a possível dicotomia entre formular e executar uma estratégia, abordada na questão 6 , obtendo a aquiesciência de $85 \%$ dos respondentes que apontaram uma dificuldade maior em colocar os planos em prática do que formulá-los.

Na Questão 2 trouxe apontado como maior obstáculo na IF estudada "estratégia vaga ou insatisfatória", seguido por "falta de diretrizes". Ao comparar os dados obtidos por Hrebiniak (2006 e 2008) e neste estudo, percebe-se que o nível de impacto dos itens considerados como de maiores obstáculos nas pesquisas do autor não repercute da mesma maneira no presente estudo. "Falta de suporte" também ganha destaque na pesquisa figurando entre os cinco obstáculos mais significativos. A comparação entre as pesquisas de Hrebiniak (2006 e 2008) e o presente estudo está apresentada no Quadro 1.

Quadro 1. Comparação - Obstáculos à Execução

\begin{tabular}{|c|c|c|c|c|c|}
\hline \multirow[t]{2}{*}{$\begin{array}{l}12 \text { Obstáculos } \\
\text { Selecionados Hrebiniak } \\
\text { (2006 e 2008) }\end{array}$} & \multirow{2}{*}{$\begin{array}{l}\text { Os } 8 \text { Principais } \\
\text { Obstáculos } \\
\text { Indicados } \\
\text { segundo } \\
\text { Hrebiniak (2006 } \\
\text { e 2008) }\end{array}$} & \multirow{2}{*}{\begin{tabular}{|l|} 
Os 8 \\
Principais \\
Obstáculos \\
Indicados \\
segundo \\
Gestores IF \\
\end{tabular}} & \multicolumn{2}{|c|}{$\begin{array}{l}\text { Os } 5 \text { Principais } \\
\text { Obstáculos segundo } \\
\text { Hrebiniak (2006 e 2008) }\end{array}$} & \multirow{2}{*}{$\begin{array}{l}\text { Os } 5 \\
\text { Principais } \\
\text { Obstáculos } \\
\text { segundo } \\
\text { Gestores IF }\end{array}$} \\
\hline & & & $\begin{array}{l}\text { Pesquisa } \\
1\end{array}$ & Pesquisa 2 & \\
\hline $\begin{array}{l}\text { Incapacidade de gerenciar } \\
\text { a mudança efetivamente } \\
\text { ou superar a resistência } \\
\text { interna à mudança }\end{array}$ & $\checkmark$ & $\checkmark$ & 1 & 1 & \\
\hline $\begin{array}{l}\text { Tentar executar uma } \\
\text { estratégia que entre em } \\
\text { conflito com a estrutura } \\
\text { existente de poder }\end{array}$ & $\checkmark$ & $\checkmark$ & 5 & 2 & 3 \\
\hline $\begin{array}{l}\text { Compartilhamento } \\
\text { deficiente ou inadequado } \\
\text { de informações entre as } \\
\text { pessoas ou unidades de } \\
\text { negócios responsáveis pela } \\
\text { execução da estratégia }\end{array}$ & $\checkmark$ & $\checkmark$ & 4 & 2 & \\
\hline $\begin{array}{l}\text { Comunicação confusa } \\
\text { de responsabilidade e/ou } \\
\text { obrigação para decisões ou } \\
\text { ações de execução }\end{array}$ & $\checkmark$ & $\checkmark$ & 5 & 4 & 4 \\
\hline $\begin{array}{l}\text { Estratégia vaga ou } \\
\text { deficiente }\end{array}$ & $\checkmark$ & $\checkmark$ & 2 & 5 & 1 \\
\hline $\begin{array}{l}\text { Falta de sentimentos } \\
\text { de "pertença" de uma } \\
\text { estratégia ou de planos } \\
\text { de execução entre os } \\
\text { principais funcionários }\end{array}$ & $\checkmark$ & $\checkmark$ & & & \\
\hline $\begin{array}{l}\text { Não ter orientações ou um } \\
\text { modelo para orientar os } \\
\text { esforços de execução da } \\
\text { estratégia }\end{array}$ & $\checkmark$ & $\checkmark$ & 2 & & 2 \\
\hline
\end{tabular}




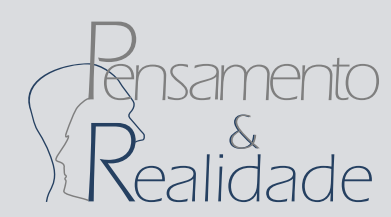

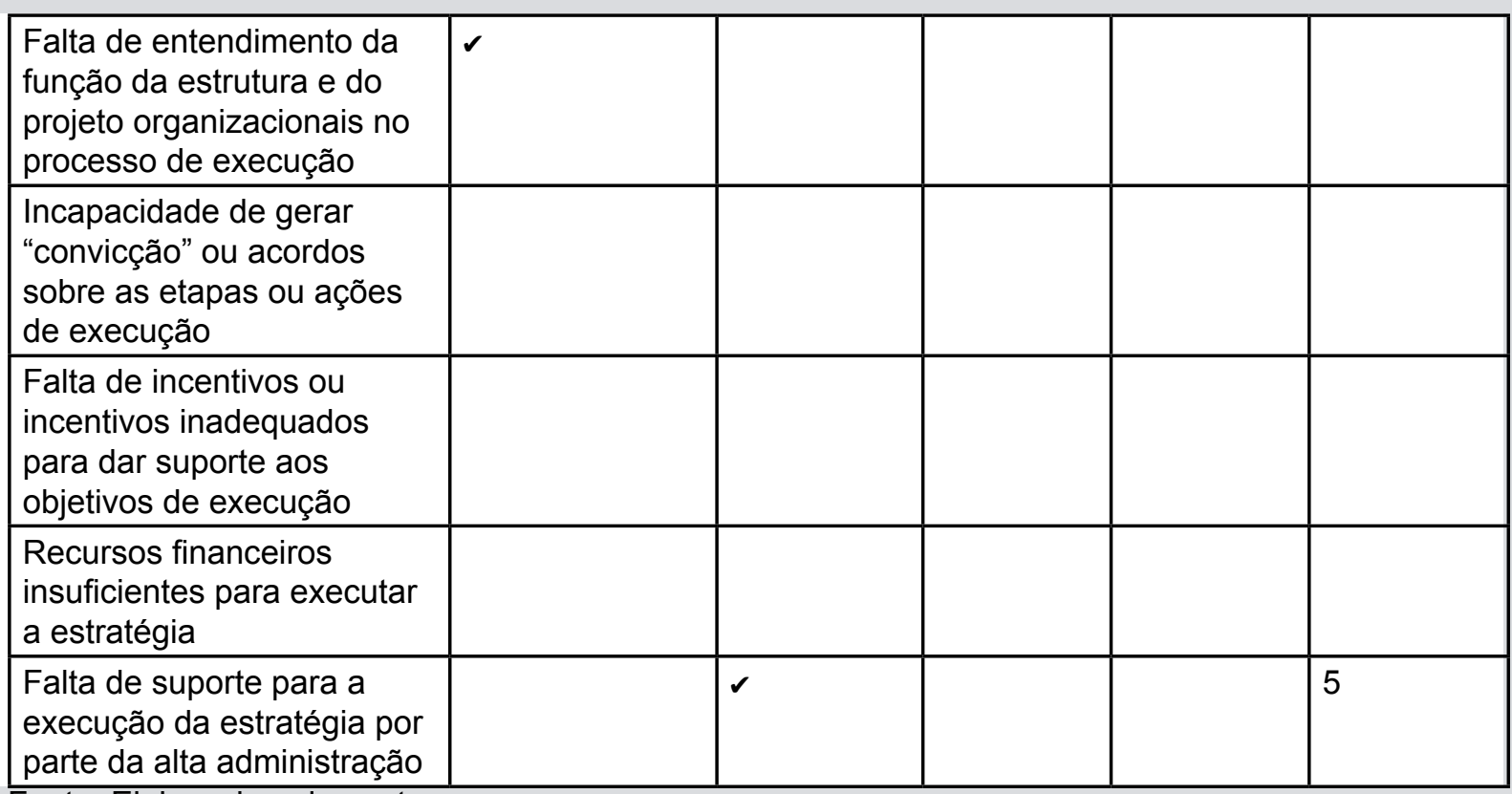

Fonte: Elaborado pelos autores

O Quadro 1 aponta a diversidade de percepção dos gestores.

As conclusões demonstradas se relacionam com o fator Obstáculos à Execução (fator 1) construído após as análises das correlações das variáveis que compuseram o questionário. Nesse fator a variável destacada é a relacionada à falta de comunicação. A divergência entre o que é apontado na figura 2 como maior obstáculo, estratégia vaga, e o apurado na análise de fatores, comunicação, deve-se ao fato de serem construídos de modos diversos, porém, sem perder a confiabilidade dos resultados. Nesse fator está a variável falta de suporte já apontada como obstáculo importante.

$\mathrm{Na}$ Questão 5 relacionam-se os fatores que levam a um diagnóstico de que a execução está em desvio estratégico. Destaques em ordem de maior relevância: "gasta-se muito tempo ou dinheiro devido à ineficiência ou burocracia no processo de execução", a demora nas decisões, empresa reage com lentidão, funcionários não sabem qual impacto do seu trabalho para os resultados, gasta-se muito tempo reorganizando, respostas demoradas, fazer política é mais importante, informações desaparecem e incerteza sobre a eficácia da estratégia que está sendo executada. Esse resultado relaciona-se ao fator 4, Indicadores de Problemas, que é composto por variáveis que ganham destaque na pesquisa como o "fazer política" e o "refazendo", ambos apontados pelos respondentes como impactantes.

$\mathrm{Na}$ Questão 8 os respondentes indicaram novos obstáculos à execução além dos previamente relacionados por Hrebiniak (2006 e 2008), apontando quais seriam os existentes no ambiente da empresa estudada por suas peculiaridades de origem, complexidade e tamanho.

Esclarece-se que foram 209 respondentes com 245 indicações de obstáculos, ou seja, mais de um obstáculo por respondente, com o fator "comunicação" em maior destaque, referendando o resultado já apontado como grande obstáculo à execução estratégica na instituição. Inferiu-se que tanto o obstáculo "comunicação" quanto o "falta ou multiplicidade de foco", que também apresenta quantidade significativa de apontamentos, tem relação com o porte da instituição, sua imensa abrangência e a grande diversidade em seu portfólio. Os resultados estão demonstrados na figura 2 e detalhados na figura 3 . 


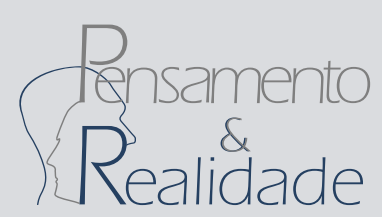

Figura 2. Obstáculos à execução na IF

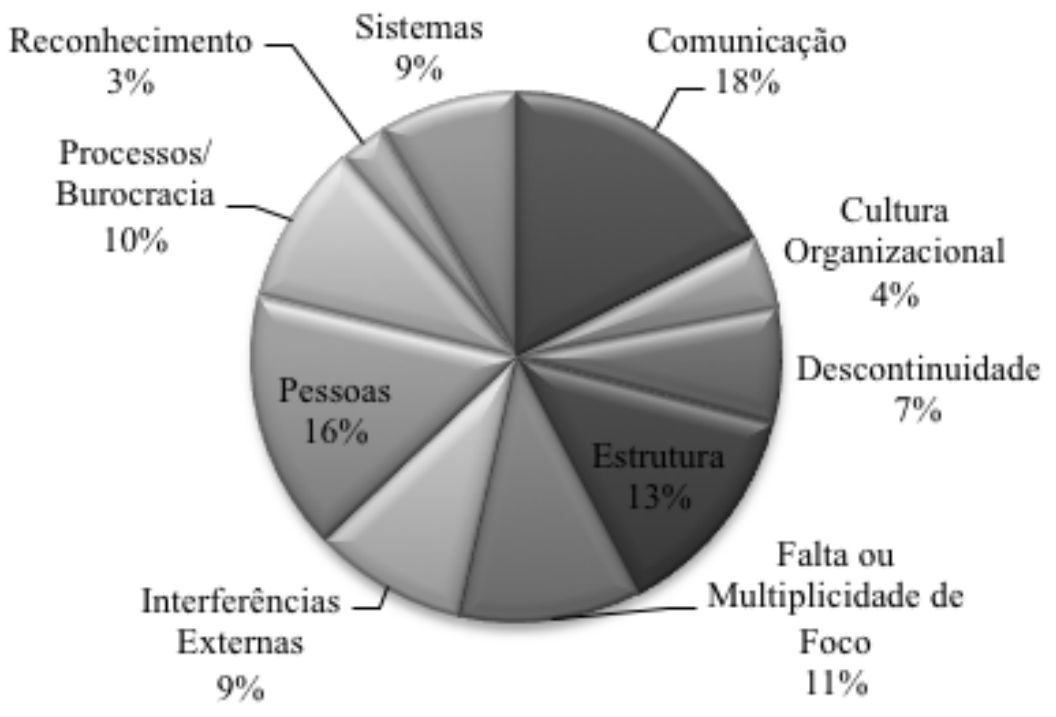

Fonte: Elaborado pelos autores

Figura 3. Comunicação: O grande obstáculo

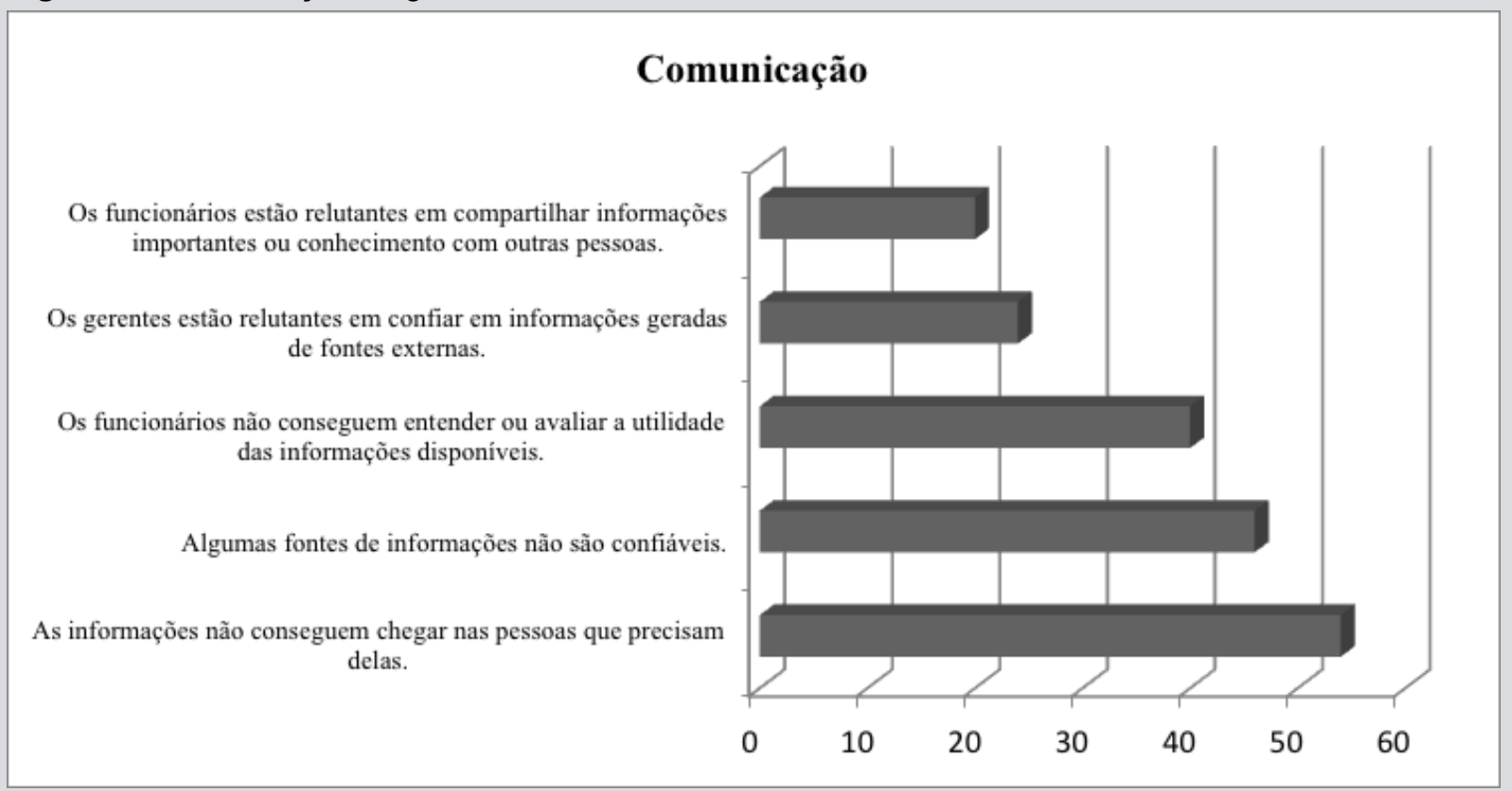

Fonte: Elaborado pelos autores

A Questão 4 abordou como obstáculo de elevado impacto para a execução estratégica os fatores ligados à comunicação. Essa indicação é apontada nas pesquisas de Devlin (1989), Beer e Eisenstat (2000), Heide et al. (2002), Mankins e Steele (2005), Kaplan e Norton (2006), Besanko et. al (2018), Hrebiniak (2006, 2008 e 2013), Cocks (2010) entre outros autores. Destacando Hrebiniak (2006, p.284 e 2008) que é categórico ao afirmar que se mostra indispensável a uma execução eficaz o desenvolvimento de um "plano de comunicação", no qual a mesma pode ocorrer individualmente ou em grupos. O autor enfatiza a necessidade de "silenciar rumores" sobre fontes de informações que distorcem a 
realidade, sob pena de insucesso. Hrebiniak (2006, p.284) declara: "Comunicação nunca é demais quando se administra a mudança de cultura". Na empresa esse assunto ganha especial destaque, como apontado na figura $2 \mathrm{e}$ confirmado na figura 3, além de ser mostrado no fator 2, denominado Informação. Fica claro, por meio dos dados extraídos e apontados nas figuras 2 e 3 que a comunicação é um obstáculo importante a ser superado e que o apontamento de equipes multifuncionais em resposta a questão 3 como solução, vem como consequência de que a instituição objeto do estudo, por suas elevadas dimensões estruturais, encontra dificuldades nesse quesito de modo destacado.

As respostas apresentadas na questão sobre BSC e Mapa Estratégico demonstram que as ferramentas são de conhecimento geral, mas não apresentam unanimidade em sua utilização. Na percepção extraída de algumas respostas: "não passam de um quadro na parede".

Destaca-se o perfil dos respondentes, cuja identificação era opcional, com o objetivo de trazer maior confiabilidade ao presente estudo. Dos que se identificaram, $53 \%$ das respostas vieram de Gerentes, 23\% de Supervisores, $14 \%$ de Superintendentes e $10 \%$ de Coordenadores. Mesmo com tamanha diversidade, o grupo se mostra aderente à pesquisa por se tratar de gestores que, com maior ou menor abrangência, tem como objetivo executar as estratégias. Outra peculiaridade é que os gestores apresentam longo tempo de carreira e de atuação como gestores.

Com a análise dos resultados obtidos, conclui-se que a instituição estudada, apresenta obstáculos à execução de sua estratégia como tantas outras organizações em diferentes localidades, mas que, por suas especificidades, enfrenta situações que ganham destaque. Para ilustrar, destacam-se igualmente os fatores 5 e 8 denominados, respectivamente, como "Desvantagem Competitiva" e "Entraves", que são compostos por variáveis importantes como lentidão e burocracia.

\section{Considerações Finais}

A execução precisa ser pensada já no processo de formulação em uma gestão integrada que possibilita superar os desafios e não deve ser rebaixada a uma atividade menos importante, quase uma consequência automática do planejamento. Segundo Hrebiniak (2006), a tarefa de implementar as iniciativas estratégicas é mais difícil que a de formulá-las, e ainda afirma que a execução não recebe um bom tratamento na maioria das organizações (Hrebiniak, 2013). A combinação de infraestrutura, recursos financeiros, tecnologia, compartilhamento e nivelamento de pensamento e valores nas equipes, habilidades pessoais, competências necessárias, alocação das pessoas certas nos lugares certos, entre outros, torna a execução mais complexa do que simplesmente colocar um plano em prática.

Este artigo objetivou identificar por que estratégias de qualidade, bem planejadas, nem sempre alcançam os resultados esperados apresentando divergências entre o que se planejou e o que foi executado, e quais fatores impactam para o alinhamento necessário. A relevância do tema, além de contribuir para a construção do conhecimento, aborda um assunto essencial para as organizações, independente de tamanho e representatividade. Por meio da realização deste estudo junto a uma instituição financeira representativa, foi possível identificar fatores de elevado impacto na execução estratégica. Os resultados das três pesquisas - duas de Hrebiniak (2006 e 2008), somadas ao estudo de caso, indicaram que os fatores de interferência eleitos pelos gestores na execução estratégica são impactados pelas diferenças ambientais.

O planejamento estratégico tem sido rígido, inflexível e um fim em si mesmo, afirmado por Mintzberg (2004), que aponta que a busca por soluções somente será possibilitada em organizações não burocráticas que se permitam aprender (Mintzberg, 2006), ou seja, a burocracia é uma das grandes responsáveis pelo entrave estratégico. $\mathrm{O}$ autor é ainda mais contundente ao destacar: "qualquer idiota 
consegue escrever um plano. É a execução que o deixa todo atrapalhado" (Mintzberg, 2004 p.108). Hrebiniak (2006 , 2008 e 2013) indica que é necessário compreender como a criação da estratégia afeta a execução e que esta envolve a necessidade de mudanças culturais, caso não exista uma disciplina para executar, e que essas mudanças precisam ser apoiadas, desenvolvidas e gerenciadas para que propiciem a adaptação das capacidades conforme mudam as estratégicas, além de estimular o compartilhamento de informações, "levando" clareza de responsabilidades e sentido de realização aos seus componentes.

Comparando as pesquisas de Hrebiniak (2006 e 2008) e os resultados obtidos no estudo, os cinco fatores elencados como de maior impacto na execução estratégica apresentam significativa diferença. Nas duas pesquisas junto às organizações abordadas pelo autor, o maior obstáculo é a incapacidade de gerenciar mudança. Já na instituição objeto do presente estudo, o grande obstáculo apontado, dentre os relacionados por Hrebiniak (2006 e 2008), foi o denominado estratégia vaga ou deficiente. Esse fator tão significativo para os gestores da instituição mostrou-se menos preocupante para os respondentes internacionais que apontaram esse obstáculo como o quinto mais importante em uma das pesquisas. A falta de suporte para a execução foi destacada neste estudo e não mereceu relevância nas pesquisas de Hrebiniak (2006 e 2008). A empresa estudada como empresa pública brasileira sofre forte impacto das questões político-econômicas nacionais, fator significativamente apontado.

Indicar categoricamente fatores impactantes para que uma estratégia seja eficazmente executada atingindo os resultados projetados, não é possível, mas por meio da presente pesquisa, é possível afirmar que: Comunicação, Alinhamento, Cultura Organizacional, Complexidade, Recursos e Revisão sobressaíram-se tanto na abordagem dos autores que compuseram a fundamentação teórica, quanto nos resultados extraídos por meio do estudo de caso. Destes fatores, a comunicação foi o maior destaque, sendo a sua ausência ou existência confusa, uma das grandes responsáveis pelos obstáculos a uma execução efetiva, trazendo alinhamento ao mencionado pelos mesmos gestores que apontaram estratégia vaga ou deficiente como o maior obstáculo organizacional dentre os relacionados por Hrebiniak (2006, 2008 e 2013), já que uma estratégia pode ser considerada "vaga" como consequência de uma comunicação falha.

Nenhuma pesquisa pode se dar como satisfeita e encerrada. Os estudos geram outras pesquisas, e com estratégia ocorre o mesmo. Os obstáculos a uma execução estratégica eficaz não estão totalmente delimitados e se mostram interdependentes, inexistindo um modelo que garanta uma formulação e execução infalíveis. Porém, é um bom indicativo o aumento de pesquisas nesse sentido, o que denota uma compreensão de que apenas formular não é suficiente. É necessário ter pensamento crítico e visão sistêmica, sem os quais não se poderá formular e tampouco executar uma estratégia que, por sua vez, não pode ser representada por uma lista de objetivos e metas ou ainda palavras de ordem motivacionais, principalmente porque em concordância com Rumelt (2011), estratégia, como competência em concentrar ações e recursos, significa fazer escolhas.

\section{Referências}

Ansoff, H. I., \& Mcdonnell, E. J.(1988). The new corporate strategy. New Jersey: John Wiley \& Sons Inc.

Baptista, M. A. A. (2013). Conselhos de administração e monitoração da

implementação estratégica: um modelo de eficácia. Tese de Doutorado. Pontifícia Universidade Católica (PUC-Rio), Rio de Janeiro.

Bauer, R. (1999). Gestão da mudança. São Paulo: Atlas

Beer, M., \& Eisenstat, R. A. (2000). The silent killers of strategy implementation and learning. Sloan Management Review, 41 (4), 29-40.

Besanko, D., Dranove, D., Shanley, M., \& Schaefer, S. (2018). A Economia da Estratégia-5.

Porto Alegre: Bookman Editora.

Bossidy, L., \& Charan, R. (2005). Execução. São 
Paulo: Elsevier Brasil.

Cândido, Carlos JF \& Santos, Sérgio P. (2019. Implementation obstacles and strategy

implementation failure, Baltic Journal of Management, 14 (1), 39-57.

Canhada, D. I. D., \& Rese, N. (2011). Implementação de estratégias: barreiras e facilitadores evidenciados na Literatura Brasileira Especializada DOI: 10.7444/fsrj. v3i1. 30. Future Studies Research Journal: Trends and Strategies, 3 (1), 38-58.

Cocks, G. (2010) Emerging concepts for implementing strategy. The TQM Journal, 22 (3), 260-266.

Crittenden, V. L., \& Crittenden, W. F. (2008) Building a capable organization: The eight levers of strategy implementation. Business Horizons, 51 (4), 301-309.

Devlin, G. (1989) How to implement a winning strategy. European Management Journal, 7 (3), 377383.

Dutra, F. A. F. \& Erdmann, R. H. (2007) Análise do planejamento e controle da produção sob a ótica da Teoria da Complexidade. Production, 17 (2), 407-419. Field, A. (2009) Descobrindo a estatística usando o SPSS-2. Porto Alegre: Bookman.

Figueiredo FILHO, D. B. \& Silva Júnior, J. A. D. (2010) Visão além do alcance: uma introdução à análise fatorial. Opinião Pública, 16 (1), 160-185.

Freedman, L. (2015) Strategy: a history. Oxford: Oxford University Press.

Fundação Dom Cabral Disponível em: http://www.fdc.org.br/programas/Paginas/ Programa.aspx? programa $=$ Estratégia $\% 20$ e $\% 20$ Execuçãofinanceiro/DC_Prudencial_1S15_final.pdf. Acesso em: 20 out. 2015.

Galpin, T. J. (2018). Realizing your strategy's potential: a seven-step model for its effective

execution. Strategy \& Leadership, 46 (6), 35-43.

Heide, M., GrØnhaug, K., \& Johannessen, S. (2002)

Exploring barriers to the successful

implementation of a formulated strategy. Scandinavian Journal of Management, 18 (2), 217-231.

Hrebiniak, L. G. (2006) Obstacles to effective strategy implementation. Organizational

dynamics, 35 (1), 12-31.

Hrebiniak, L. G. (2008). Fazendo a estratégia funcionar. Porto Alegre: Bookman.

Hrebiniak, L. G. (2013). Making strategy work: Leading effective execution and change. FT

Press.

Kaplan, R. S., \& Norton, D. P. (2006) Alinhamento: utilizando o Balanced Scorecard para

criar sinergias corporativas. Rio de Janeiro: Campus.

Kich, J. I. D. F., Pereira, M. F., Emmendoerfer, M. L. , $\&$ dos Santos, A. M. (2008) A

influência do líder na condução do processo de implementação do planejamento estratégico. Revista de Ciências da Administração, 10 (21) 122-146.
Kim, C., \& Mauborgne, R. (2005) A estratégia do Oceano Azul - Como criar novos mercados

e tornar a concorrência irrelevante. Rio de Janeiro: Campus 2005.

Mankins, M. C., \& Steele, R. (2005) Turning great strategy into great performance. Harvard

Business Review, 2607.

Mintzberg, H. (2004). Ascensão e queda do planejamento estratégico. Porto Alegre:

Bookman.

Mintzberg, H. (2006). O Processo da Estratégia - 4. Porto Alegre: Bookman.

Mintzberg, H., Ahlstrand, B., \& Lampel, J. (2010).

Safári da estratégia. Porto Alegre:

Bookman.

Mitchell, D., Larson, S. E., Colantonio, C., \& Nguyen, C. (2018). Planning for Change:

Incorporating Contextual Implementation Design into Strategic Planning. State and Local Government Review, 50(2), 110-118.

Nalebuff, B. J., \& Brandenburger, A. M. (1996). Coopetição. Rio de Janeiro: Rocco, 28-35.

Neilson, G. L., Martin, K. L., \& Powers, E. (2008). The secrets to successful strategy execution. Harvard Business Review Press, 86, (6), 60.

Porter, M. E. (1996a) Estratégia competitiva: técnicas para análise de indústrias e da concorrência. Rio de Janeiro: Campus.

Porter, M. E. (1996b). Vantagem competitiva: criando e sustentando um desempenho superior. Rio de Janeiro: Campus.

Porter, M. E. (2009). Competição. Edição revista e ampliada. Rio de Janeiro: Editora Campus.

Raffoni, M. (2003). Three keys to effective execution. Harvard Management Update, 8, (2), 1-4.

Ritson, G., Johansen, E., \& Osborne, A. (2012). Successful programs wanted: exploring the impact of alignment. Project Management Journal, 43 (1), 21-36. Rumelt, R. P. (2011). Estratégia boa, estratégia ruim: descubra suas diferenças e importância. Rio de Janeiro: Elsevier.

Slater, S. F., Olson, E. M., \& Hult, G. T. M. (2010). Worried about strategy implementation? Don't overlook marketing's role. Business Horizons, 53, (5), 469-479.

Survey Monkey - Disponível em: https:// pt.surveymonkey.com. Acesso: de nov./2015 a maio/2016.

Wernerfelt, B. (1984). A resource-based view of the firm. Strategic management journal, 5 (2), 171-180.

Yin, R. K. (2001). Estudo de caso. Planejamento e métodos. Tradução de Daniel Grassi. 2.ed. Porto Alegre: Bookman. 